\title{
Combined Effects of Dibutyl Phthalate (DBP) and Benzo(a)Pyrene on Fertility in Male Rats
}

\author{
Yujing Huang, Ji'an Chen, Weiqun Shu* \\ Department of Environmental Hygiene, College of Preventive Medicine, Third Military Medical University, \\ Chongqing, China \\ Email: west2003@sohu.com
}

Received December 2013

\begin{abstract}
Our previous studies revealed the polycyclic aromatic hydrocarbon and phthalic acid esters were the major organic pollutants in the Jialing River and Yangtze River in the Three Gorges area, and they might cause the toxicity in male fertility when combined. Thus we used di-n-butyl phthalate (DBP) and Benzo(a)pyrene (Bap) as their representatives respectively to explore their effects on the spermatogenesis in male rats. Male Sprague Dawley rats were randomly divided into 4 groups and respectively exposed to corn oil, Bap (5 mg/ $\mathrm{kg} / \mathrm{d})$, DBP $(250 \mathrm{mg} / \mathrm{kg} / \mathrm{d})$, and combined doses of Bap (5 mg/ $/ \mathrm{kg} / \mathrm{d})$ and DBP $(250 \mathrm{mg} / \mathrm{kg} / \mathrm{d})$ for 90 days. We observed a significant increase in the stillbirth rate after Bap and combined treatments, while the mean area of seminiferous tubules was reduced after Bap, DBP and combined treatments. Bap and combined treatment had a suppressing effect on meiosis in germ cells, which reduced the haploid contents and the ratio between haploid and diploid but increased the tetraploid and diploid contents and the ratio between haploid and tetraploid. These effects were more obvious in the combined group. Furthermore, the expression of a number of proteins was changed, of which was associated with the oxidative stress and CAMP/PKA signaling pathway. Our results suggest that Bap has significant toxic effects on male fertility, while the combined treatment of Bap and DBP has more toxic effects.
\end{abstract}

\section{Keywords}

Di-n-Butyl Phthalate; Benzo(a)Pyrene; Male Reproductive; Protein Expression; Tubules Structure; Spermatogenesis

\section{Introduction}

Di-n-butyl phthalate (DBP), a representative of phthalate acid esters (PAEs) that have been used in a wide variety of industrial and common household products, can induce the atrophy in the testes and seminiferous tubules, reproductive tract malformation, the change in enzyme activity in testicular cells, hormone reduction,

\footnotetext{
${ }^{*}$ Corresponding author.
} 
spermatogenic cell apoptosis and sperm counts reduction (Kavlock et al., 2002; Shultz et al., 2001; M. S. Alam et al., 2010a; M. S. Alam et al., 2010b). Benzo(a)pyrene (Bap), a prototype of polycyclic aromatic hydrocarbon (PAH) that is released into the environment by industrial emission, has attracted worldwide attention as its toxic effect on male reproduction. It has been demonstrated that Bap can cause seminiferous tubules malformation, change the epididymis function and enzyme activity in testicular cells, induce DNA damage and synthesis inhibition in spermatogenic cells, and decrease serum testosterone level and the amount of spermatogenic cells and sperms (Zhu et al., 2010; Sipinen et al., 2010; Inyang et al., 2003; Mohammad Shah Alam et al., 2010; Ramesh et al., 2008).

In our previous study, PAHs and PAEs are the most organic pollutants in the Jialing river and Yangtze river in Three Gorges area (Chen et al., 2008). The organic extracts from Jialing River in Chongqing can cause pathological damage and peroxidation response to testis (Cui et al., 2010). When we chose DBP and Bap as model compounds, we found that in vivo exposure to DBP and Bap, either separately or in combination, resulted in adverse effects on the reproductive system of male rats, including disturbing the secretion of $\mathrm{T}$, influencing the production and morphology of sperm and damaging the seminiferous tubule, which may induced through oxidative stress from their ROS-metabolites (Qing, 2009; QIU et al., 2009; Huang et al., 2010; Chen et al., 2011). And the adverse effects in rats exposed to the DBP and Bap are unexpected and elusive, which suggesting a further investigation is needed to explore the complex mechanism of action of these organic pollutions in greater detail.

In this study, we investigated whether the reproductive toxicity of Bap and DBP can affect the male fertility and explored the possible mechanisms. Our study provides strong evidences for the toxic effects of Bap and DBP on male fertility.

\section{Methods}

\subsection{Animals and Treatment}

Male Sprague Dawley (SD) rats ( $\mathrm{n}=48,4$ to 5 weeks of age) were provided by the Laboratory Animal Center of Third Military Medical University (TMMU, China). This study was approved by the Third Military Medical University Institutional Animal Care and Use Committee. All rats were housed in polycarbonate cages with chip hardwood, allowed to access to food and filtered tap water ad libitum and maintained at $20^{\circ} \mathrm{C}-22^{\circ} \mathrm{C}$ and $50 \%$ $70 \%$ humidity with controlled lighting (12 h light/12 h darkness).

DBP (Cat. No. 84-74-2, 99\% purity), Bap (Cat. No. 50-32-8, 96\% purity) and corn oil (Cat. No. 8001-30-7) were purchased from Sigma Aldrich (St. Louis, MO). After one week acclimatization period, male SD rats were randomly assigned into 4 groups (12 per group) and administrated corn oil (Control group), 5 mg/kg Bap (Bap group), $250 \mathrm{mg} / \mathrm{kg}$ DBP (DBP group), combination of $5 \mathrm{mg} / \mathrm{kg}$ Bap and $250 \mathrm{mg} / \mathrm{kg}$ DBP (Combined group) each day at the same time via gavage for 90 days. After treatment, 8 rats in each group were anesthetized deeply with $20 \%$ urethane and sacrificed to collect the testes. Other rats $(n=4)$ were mated with health female SD rats (22 - 24 weeks, 1:1 randomly matched). The day on which the vaginal plug was observed was set as the 1st day of pregnancy. Pregnant rats were anesthetized with $20 \%$ urethane and sacrificed on the 20th day of pregnancy. The fetuses were separated to examine the total stillbirth rate (including absorptive fetus).

\subsection{Examination of Histopatological Testes}

The left testes from each group were fixed in Bouin's fixative at room temperature for 72 h. Following infiltrating and embedding with paraffin wax, serial sections $(4 \mu \mathrm{m})$ were cut from the middle of each testis preparation. Sections were stained with haematoxylin and eosin (HE), observed and evaluated on a light microscope (BX51) equipped photomicroscope (DP72; OLYMPUS) which coupled with a computerized morphometric planimetry system (DP72-BSW; OLYMPUS) to facilitate the measurement of tubule area and area percentage (volume percentage) occupied by seminiferous tubules. The percentage of seminiferous tubules was computed according to Ramesh (Ramesh et al., 2008).

\subsection{Germ Cell Preparation}

Right testes without albuginea were washed and decapsulated by phosphate buffer saline (PBS) (Zhongshan golden bridge Biotechnology Co., Ltd., Beijing, China). Seminiferous tubules were separated with pipette, 
washed and sedimentated in PBS and discarded supernatant. Separated seminiferous tubule fragments were incubated in PBS containing $1 \mathrm{mg} / \mathrm{ml}$ type IV collagenase (C5138, sigma) for $20 \mathrm{~min}$ at $37^{\circ} \mathrm{C}$, washed and pipetted in PBS three times. After each wash, the supernatant was discarded. The pellet were incubated in $0.25 \%$ trypsogen (SH30042.01, HyClone, Thermo Scientific, Pittsburgh, PA) for $10 \mathrm{~min}$ at $37^{\circ} \mathrm{C}$, then mixed with equal volume of DMEM/F12 (SH30023.01, HyClone) medium containing 10\% bovine calf serum (Sijiqing Biological Engineering Materials Co., Ltd., Hangzhou, China). The samples were centrifuged at $100 \times \mathrm{g}$ for 3 min to remove the supernatant, and then washed in PBS three times. The pellet was composed of the mixture of germ cells and the purity was assessed by the staining of vimentin that is expressed in other cells (including sertoli cells, interstitial cells and peritubular cells) of testes but not in the germ cells.

\subsection{Flow Cytometric Analysis (FCM) of DNA Content in Isolated Germ Cells}

The mixture of germ cells was fixed in $70 \%$ ethanol and washed twice in PBS. Then incubated with $1 \mathrm{mg} / \mathrm{ml}$ RNase for $30 \mathrm{~min}$ at $37^{\circ} \mathrm{C}$ and stained by propidium iodide (PI) for $30 \mathrm{~min}$ at $4{ }^{\circ} \mathrm{C}$. The fluorescent signals of PI-stained cells were recorded using a flow cytometer (FACSCalibur; BD Immunocytometry Systems, San Diego, CA) and then analyzed by CellQuest (BD Immunocytometry Systems). According to DNA content, germ cells were divided into 4 phases, including haploid (1C) that is round and elongated spermatids, diploid (2C) that is spermatogonia, tetraploid (4C) that is primary spermatocytes, and S-phase in which the cells can actively synthesize DNA. The germ cell ratios among haploid, diploid and tetraploid were determined by 1C:4C, 1C:2C, 4C:2C.

\subsection{Two-Dimensional Electrophoresis (2-DE) and the Identification of Differential Proteins in Isolated Germ Cells by Proteomics Method}

The germ cells mixture was suspended in cell lysate (8 M urea (GibcoBRL), 4\% CHAPS (Calbiochem), $40 \mathrm{mM}$ Tris base (GibcoBRL), 1 mM PMSF (Pierce Chemicals, Rockford, IL), 2 mM EDTA (GibcoBRL), 10 mM DDT (Promega, Madison, WI)) and sonicated for $5 \mathrm{~min}$ on ice by a ultrasonic vibrator (JY92-II; Scientz, Ningbo, China) and centrifuged at $12,000 \times \mathrm{g}$ for $20 \mathrm{~min}$. The protein concentration in supernatant was measured by Bradford method and the samples were stored at $-80^{\circ} \mathrm{C}$.

The 2-DE was carried out using pre-cast IPG strip (pH 3-10; $7 \mathrm{~cm}$ ) gels (three parallel samples per group) on an IPGphor unit (IPGphor, Amersham Biosciences, Piscataway, NJ), followed by the second dimension using pre-cast polyacrylamide gel (Ettan DALT II Gel, Amersham Biosciences) on a vertical electrophoresis system (Ettan DALT SIX, Amersham Biosciences) following user's manual (Amersham Biosciences). The gels were stained with the Plus One Silver Staining Kit (Amersham Biosciences) using the Multi-Processor (Amersham Biosciences) and scanned and analyzed with the ImageMaster 5.00 analysis software (Amersham Biosciences).

For the identification of protein spots by mass spectrometry, the protein spots were cut into $1.5 \mathrm{~mm}$ cubes, faded in a 50\% CAN (Fisher), digested with trypsin (Promega) and analyzed by using delayed extraction matrix-assisted laser desorption/ionization (MALDI) time-of-flight (TOF) mass spectrometer system (Bruker Ultraflex). Monoisotopic peptide masses obtained from MALDI-TOF were queried against the entries for protein databases in NCBI using a protein search program, Mascot (Matrix Science Ltd., London).

\section{Results and Discussion}

\subsection{The Effect of DBP and Bap on Rat Growth}

Compared with control rats, the rats after Bap and DBP treatments did not show the change in weekly weight gains $(P \geq 0.05)$, and the organ coefficients of heart, spleen, kidney, liver, epididymis and testis were not changed $(P \geq 0.05)$.

\subsection{The Effect of DBP and Bap on Rat Fertility, Histological Changes and Cell Cycle in Testes}

There was no difference in the pregnancy rate among different groups $(P \geq 0.05)$. The stillbirth rate (including absorptive fetus) was significantly increased after Bap treatment and the combined treatment of Bap and DBP compared to control $(P<0.05)$. The atrophy in the seminiferous tubules was observed in all groups treated with 
Bap, DBP, and both $(P<0.05)$. The atrophy in the Bap group was lighter than that in the DBP and combined groups $(P, 0.05 \mathrm{~B})$. However, there was no significant difference in the percentage of seminiferous tubules in testis among four groups $(P \geq 0.05)$. Compared with the control group, the proportion of different germ cell populations and their ratios were not changed after treatments with DBP and Bap, while in the combined group, the haploid content and the ratio of 1C:4C was significantly reduced $(P<0.05)$ but the tetraploid contents and the ratio of 4C:2C were significantly increased, even compared with the Bap group $(P<0.05)$. These data indicate that the combined treatment with Bap and DBP may induce a suppressing effect on the meiosis in germ cells in testes.

\subsection{The Changes in Total Protein Expression}

2-DE was used to separate the proteins, and the results from ImageMaster 2D Platinum 5.0 analysis screened 35 different proteins between control and treated groups. 21 proteins were identified by mass spectrometric analysis and 4 proteins were identified as Serum albumin.

Bap, DBP and their combined exposure could decreases SOD and GSH-Px activities and increase CAT activity, which indicates an oxidative stress state in the testis (Chen et al., 2011). In this study, the expression of many proteins which associated with oxidative stress was changed in the germ cells after treatments with Bap and DBP and may associate with their reproductive toxicology. PKA C-beta and tubulin beta-5, which would be associated with germ cell structure, meiosis process and male fertility (Burton et al., 2006; Fujimori et al., 2012), were up-regulated after treatment with Bap. HnRNP DL, which acted as a transcriptional regulator and was associated with cell cycle (Akagi et al., 2000), also varied when exposed to Bap. Both of them are associated with the structural defects, the suppression on meiosis process and adverse effects on male fertility. All these proteins and others, including Mitofilin, Rho GTPase activating protein 11A and MST4, are associated with cAMP/PKA signal pathway, which may be activated by the oxidative stress (Barlow et al., 2006). Other oxidative stress associated proteins like serotransferrin, ECE-2, retinoid binding protein, endoplasmin, hemopexin and ALDH2 were also associated with Bap and DBP exposure (Klipper et al., 2010). Suggesting that the exposure of Bap and DBP may disturb the oxidant/antioxidant balance and active the cAMP signal pathway in germ cells (Arafa et al., 2009; Mayati et al., 2012). Mitofilin, endoplasmin and MST4 are also associated with apoptotic process. The change of their expression in germ cells those are exposed to Bap may be associated with the atrophy in the seminiferous tubules and structural defects. The structural damage in the Bap group included blood-testis barrier disruption, which can be the reason of enhanced expression of tubulin beta and albumin (Liao et al., 2006; Christensen et al., 1985).

\section{Conclusion}

Our data demonstrated that in vivo exposure to Bap and DBP resulted in directly adverse effects on germ cells and spermatogenesis, which may be associated with oxidant/antioxidant balance and activation of the cAMP/ PKA signaling pathway, and the reproductive toxicity of combined exposure is stronger than individual exposure.

\section{Acknowledgements}

This work was supported by a Key Project of National Natural Science Foundation of China (No. 30630056) and the Natural Science Foundation of China (Grant No. 81072262).

\section{References}

Akagi, T., Kamei, D., Tsuchiya, N., Nishina, Y., Horiguchi, H., Matsui, M. et al. (2000). Molecular Characterization of a Mouse Heterogeneous Nuclear Ribonucleoprotein D-Like Protein JKTBP and Its Tissue-Specific Expression. Gene, 245, 267-273. http://dx.doi.org/10.1016/S0378-1119(00)00032-9

Alam, M. S., Andrina, B. B., Tay, T. W., Tsunekawa, N., Kanai, Y., \& Kurohmaru, M. (2010). Single Administration of Di(n-butyl) Phthalate Delays Spermatogenesis in Prepubertal Rats. Tissue and Cell, 42, 129-135. http://dx.doi.org/10.1016/j.tice.2010.02.004

Alam, M. S., Ohsako, S., Matsuwaki, T., Zhu, X. B., Tsunekawa, N., Kanai, Y. et al. (2010a). Induction of Spermatogenic Cell Apoptosis in Prepubertal Rat Testes Irrespective of Testicular Steroidogenesis: A Possible Estrogenic Effect of 
Di(n-butyl) Phthalate. Reproduction, 139, 427-437. http://dx.doi.org/10.1530/REP-09-0226

Alam, M. S., Ohsako, S., Tay, T. W., Tsunekawa, N., Kanai, Y., \& Kurohmaru, M. (2010b). Di(n-butyl) Phthalate Induces Vimentin Filaments Disruption in Rat Sertoli Cells: A Possible Relation with Spermatogenic Cell Apoptosis. Anatomy Histology and Embryology, 39, 186-193. http://dx.doi.org/10.1111/j.1439-0264.2010.00993.x

Arafa, H. M., Aly, H. A., Abd-Ellah, M. F., \& El-Refaey, H. M. (2009). Hesperidin Attenuates Benzo[Alpha] Pyrene-Induced Testicular Toxicity in Rats via Regulation of Oxidant/Antioxidant Balance. Toxicology and Industrial Health, 25, 417-427. http://dx.doi.org/10.1177/0748233709106624

Barlow, C. A., Shukla, A., Mossman, B. T., \& Lounsbury, K. M. (2006). Oxidant-Mediated cAMP Response Element Binding Protein Activation: Calcium Regulation and Role in Apoptosis of Lung Epithelial Cells. American Journal of Respiratory Cell and Molecular Biology, 34, 7-14. http://dx.doi.org/10.1165/rcmb.2005-0153OC

Burton, K. A., McDermott, D. A., Wilkes, D., Poulsen, M. N., Nolan, M. A., Goldstein, M. et al. (2006). Haploinsufficiency at the Protein Kinase A RI Alpha Gene Locus Leads to Fertility Defects in Male Mice and Men. Molecular Endocrinology, 20, 2504-2513. http://dx.doi.org/10.1210/me.2006-0060

Chen, J. A., Luo, J., Qiu, Z., Xu, C., Huang, Y., Jin, Y. H. et al. (2008). PCDDs/PCDFs and PCBs in Water Samples from the Three Gorge Reservoir. Chemosphere, 70, 1545-1551. http://dx.doi.org/10.1016/j.chemosphere.2007.08.063

Chen, X., An, H., Ao, L., Sun, L., Liu, W., Zhou, Z. et al. (2011). The Combined Toxicity of Dibutyl Phthalate and Benzo(a)Pyrene on the Reproductive System of Male Sprague Dawley Rats in Vivo. Journal of Hazardous Materials, 186, 835-841. http://dx.doi.org/10.1016/j.jhazmat.2010.11.078

Christensen, A. K., Komorowski, T. E., Wilson, B., Ma, S. F., \& Stevens 3rd, R. W. (1985). The Distribution of Serum Albumin in the Rat Testis, Studied by Electron Microscope Immunocytochemistry on Ultrathin Frozen Sections. Endocrinology, 116, 1983-1996. http://dx.doi.org/10.1210/endo-116-5-1983

Cui, Z., Liu, J., Li, P., \& Cao, J. (2010). Male Reproductive and Behavior Toxicity in Rats after Subchronic Exposure to Organic Extracts from Jialing River of Chongqing, China. Birth Defects Research. Part B, Developmental and Reproductive Toxicology, 89, 34-42.

Fujimori, C., Ogiwara, K., Hagiwara, A., \& Takahashi, T. (2012). New Evidence for the Involvement of Prostaglandin Receptor EP4b in Ovulation of the Medaka, Oryzias Latipes. Molecular and Cellular Endocrinology, 362, 76-84. http://dx.doi.org/10.1016/j.mce.2012.05.013

Huang, Y., Chen, J.-A., \& Shu, W. (2010). Subchronic Toxic Effects of Exposure in Combination to Dibutyl Phthalate and Benzo[a]Pyrene on Spermatogenesis in Male Rats. Journal of Environmental Health, 27, 215-218.

Inyang, F., Ramesh, A., Kopsombut, P., Niaz, M. S., Hood, D. B., Nyanda, A. M. et al. (2003). Disruption of Testicular Steroidogenesis and Epididymal Function by Inhaled Benzo(a)Pyrene. Reproductive Toxicology, 17, 527-537. http://dx.doi.org/10.1016/S0890-6238(03)00071-6

Kavlock, R., Boekelheide, K., Chapin, R., Cunningham, M., Faustman, E., Foster, P. et al. (2002). NTP Center for the Evaluation of Risks to Human Reproduction: Phthalates Expert Panel Report on the Reproductive and Developmental Toxicity of Di-n-butyl Phthalate. Reproductive Toxicology, 16, 489-527. http://dx.doi.org/10.1016/S0890-6238(02)00033-3

Klipper, E., Levit, A., Mastich, Y., Berisha, B., Schams, D., \& Meidan, R. (2010). Induction of Endothelin-2 Expression by Luteinizing Hormone and Hypoxia: Possible Role in Bovine Corpus Luteum Formation. Endocrinology, 151, $1914-1922$. http://dx.doi.org/10.1210/en.2009-0767

Liao, X., Terada, N., Ohno, N., Li, Z., Fujii, Y., Baba, T. et al. (2006). Immunohistochemical Study of Serum Albumin in Normal and Cadmium-Treated Mouse Testis Organs by “in Vivo Cryotechnique”. Histology and Histopathology, 21, 3540.

Mayati, A., Levoin, N., Paris, H., N’Diaye, M., Courtois, A., Uriac, P. et al. (2012). Induction of Intracellular Calcium Concentration by Environmental Benzo(a)Pyrene Involves a Beta2-Adrenergic Receptor/Adenylyl Cyclase/Epac-1/Inositol 1,4,5-Trisphosphate Pathway in Endothelial Cells. The Journal of Biological Chemistry, 287, 4041-4052. http://dx.doi.org/10.1074/jbc.M111.319970

Qing, Z. (2009). Effects of Di-n-butyl Phthalate on Testicular Insl3 mRNA Expression in Pubertal Male Rats. Carcinogenesis, Teratogenesis and Mutagenesis, 21, 0161-0164.

Qiu, Z.-Q., Shu, W.-Q., Chen, J., Luo, J.-H., Yang, L., Zheng, Y.-K. et al. (2009). Combined Effect of Di-n-butyl Phthalate and Benzo(a) Pyrene on Vimentin and $\alpha$-Tubulin in Rat Sertoli Cells. Carcinogenesis, Teratogenesis and Mutagenesis, 21, 0165-0168.

Ramesh, A., Inyang, F., Lunstra, D. D., Niaz, M. S., Kopsombut, P., Jones, K. M. et al. (2008). Alteration of Fertility Endpoints in Adult Male F-344 Rats by Subchronic Exposure to Inhaled Benzo(a)Pyrene. Experimental and Toxicologic Pathology, 60, 269-280. http://dx.doi.org/10.1016/j.etp.2008.02.010

Shultz, V. D., Phillips, S., Sar, M., Foster, P. M., \& Gaido, K. W. (2001). Altered Gene Profiles in Fetal Rat Testes after in Utero Exposure to Di(n-butyl) Phthalate. Toxicological Sciences, 64, 233-242. http://dx.doi.org/10.1093/toxsci/64.2.233 
Sipinen, V., Laubenthal, J., Baumgartner, A., Cemeli, E., Linschooten, J. O., Godschalk, R. W. et al. (2010). In Vitro Evaluation of Baseline and Induced DNA Damage in Human Sperm Exposed to Benzo[a]Pyrene or Its Metabolite Benzo[a]Pyrene-7,8-diol-9,10-epoxide, Using the Comet Assay. Mutagenesis, 25, 417-425. http://dx.doi.org/10.1093/mutage/geq024

Zhu, X. B., Tay, T. W., Andriana, B. B., Alam, M. S., Choi, E. K., Tsunekawa, N. et al. (2010). Effects of Di-iso-butyl Phthalate on Testes of Prepubertal Rats and Mice. Okajimas Folia Anatomica Japonica, 86, 129-136.

http://dx.doi.org/10.2535/ofaj.86.129 